\section{Reply to Liccardi et al}

Sastre J

Department of Allergy, Fundación Jimenez Diaz, Madrid, Spain

J Investig Allergol Clin Immunol 2016; Vol. 26(6): 406 doi: 10.18176/jiaci.0106

Key words: Siberian hamster. Rhinitis. Asthma. Allergy to pets.

Palabras clave: Hámster siberiano. Rinitis. Asma. Alergia a animales domésticos.

\section{To the Editor:}

In this issue of the Journal of Investigational Allergology and Clinical Immunology, Liccardi et al comment on our article on the clinical characteristics of patients sensitized to Siberian hamster [1] and draw attention to the high risk of sensitization to other furry animals if a patient is already sensitized to common pets. This affirmation is completely correct. The authors provide a diagnostic flowchart for susceptible individuals who wish to own a Siberian hamster. In this flowchart they mention the need for specific IgE to this pet. However, it is important to remember that extracts from Siberian hamster are not commercially available and must therefore be made in-house. It is also noteworthy that allergens from Siberian hamster do not cross-react with those of the European and Golden hamster or with other lipocalins from cat or dog [2,3]. None of the patients in our study were sensitized to albumin $[2,3]$; therefore, its role does not seem to be important. In a recent study by our group [4], only $9 \%$ of patients with allergy to cat, dog, and horse were sensitized to albumins. Nevertheless, since these patients had more severe respiratory disease, sensitization can be considered a biomarker of severity.

\section{References}

1. Torres JA, Sastre J, Vivanco F, Sanz Maroto A, de Las Heras M, Pastor-Vargas C. Clinical Characteristics of Patients Sensitized to Siberian Hamster. J Investig Allergol Clin Immunol. 2016;26(2):113-5.

2. Torres JA, de Las Heras M, Maroto AS, Vivanco F, Sastre J, PastorVargas C. Molecular and immunological characterization of the first allergenic lipocalin in hamster: the major allergen from Siberian hamster (Phodopus sungorus). J Biol Chem. 2014 Aug 22;289(34):23382-8

3. Torres JA, Pastor-Vargas C, de las Heras M, Vivanco F, Cuesta J, Sastre J. An odorant-binding protein as a new allergen from Siberian hamster (Phodopus sungorus). Int Arch Allergy Immunol. 2012;157(1):109-12

4. Uriarte SA, Sastre J Clinical relevance of molecular diagnosis in pet allergy. Allergy. 2016 Jul;71(7):1066-8.

- Manuscript received July 27, 2016; accepted for publication July 29, 2016.

\section{- Joaquín Sastre}

Department of Allergy Fundación Jimenez Diaz Avda. Reyes Católicos 2 28040 Madrid, Spain E-mail: jsastre@fjd.es 